\title{
Structure and Performance of Spherical Natural Graphite Modified by Ag-C Double Coating
}

\author{
Chun-ping Hou ${ }^{1,2}$, Hao Zhang ${ }^{1}$, Yong Ma ${ }^{1}$, Wang-chang Geng ${ }^{1}$ and Qiu-yu Zhang, ${ }^{1, *}$ \\ ${ }^{1}$ School of Science, Northwestern Polytechnical University, Xi'an Shaanxi, 710129, P.R. China \\ ${ }^{2}$ Ningxia BOLT Technologies Co., Ltd., Yinchuan Ningxia, 750011, P.R. China \\ "E-mail: qyzhang@nwpu.edu.cn
}

doi: $10.20964 / 2017.05 .59$

Received: 11 February 2017 / Accepted: 22 March 2017 / Published: 12 April 2017

\begin{abstract}
A liquid-phase method was used to prepare a novel Ag-C double-coated graphite composite anode material. In this method, Ag is deposited on the surface of spherical natural graphite by electroless plating, and the excessive glucose in the solution, which is used as a reductant in the silver mirror reaction, acts as a carbon coating. X-ray diffraction (XRD) and scanning electron microscopy (SEM) have been employed to investigate the microstructure and morphology of the as-prepared samples. Electrochemical tests showed that good low-temperature performance, large rate capability, and good cycle performance have been obtained from the Ag-C double coated graphite composite anode material; thus, it is suitable for power or energy storage batteries. The sample with a content of 0.9 wt\% Ag showed the best comprehensive performance with a discharge capacity of $65.2 \mathrm{mAh} \mathrm{g}^{-1}$ when discharged at $0.1 \mathrm{C}$ rate and at $-20{ }^{\circ} \mathrm{C}$, which is almost double the discharge capacity of the control sample.
\end{abstract}

Keywords: Natural graphite; Low-temperature performance; Liquid-phase; Double coating

\section{FULL TEXT}

(C) 2017 The Authors. Published by ESG (www.electrochemsci.org). This article is an open access article distributed under the terms and conditions of the Creative Commons Attribution license (http://creativecommons.org/licenses/by/4.0/). 